Dikirim: 19 Juni 2017

Diterbitkan: 1 Oktober 2017

\section{Komunikasi orang tua tentang seksualitas terhadap perilaku seksual pranikah remaja}

Parents' communication about sexuality to premarital sexual behavior in adolescents

Isna Wanufika ${ }^{1}$, Sumarni $^{2}$, Djauhar Ismail $^{3}$

\begin{abstract}
Purpose: This research aimed to examine the relationship between parent-child communication about sexuality and adolescents premarital sexual behavior. Methods: This research involved 205 students in Senior High School "A" Yogyakarta. Data analysis was conducted with chi-square and logistic regression tests. Results: This research showed that there was no significant correlation $(p>0.05)$ between parental communication about sexuality and premarital sexual behavior in adolescents with OR score 1.43 (95\% Cl; 0.78- 2.63). The results of parental communication analysis of sexuality after considering other variables: such as gender, self-efficacy, and alcohol / drug used accounted for $5.7 \%$ in at risk premarital sexual behavior. Conclusion: There were no significant correlations between parent-child communication about sexuality and adolescents' premarital sexual behavior.
\end{abstract}

Keywords: parent-child communication; premarital sexual behavior; adolescent

\footnotetext{
${ }^{1}$ Departemen Biostatistik, Epidemiologi, dan Kesehatan Populasi, Fakultas Kedokteran, Universitas Gadjah Mada (Email: isnaawf@yahoo.com)

${ }^{2}$ Departemen Psikiatri dan Psikologi Klinis, Fakultas Kedokteran, Universitas Gadjah Mada

${ }^{3}$ Bagian Tumbuh Kembang, Fakultas Kedokteran, Universitas Gadjah Mada
} 


\section{PENDAHULUAN}

Masa remaja adalah masa peralihan tahap anak menuju dewasa. Perkembangan seksual terjadi pada masa remaja (10-19 tahun), termasuk perkembangan kematangan jasmani, seksualitas, pikiran, dan emosional. Secara ideal, pada masa ini remaja telah memperoleh pengetahuan memadai tentang seks, namun karena ketidaksiapan remaja menghadapi perubahan psikis (kejiwaan dan mental) dalam diri termasuk peningkatan dorongan seks yang tidak mampu dikontrol, maka tidak jarang remaja melakukan penyimpangan perilaku seks pranikah, pelanggaran norma-norma dan konflik dalam diri remaja (1).

Hasil statistik dari Youth Risk Behavior Surveillance Survey tahun 2013 menunjukkan bahwa 46,8\% remaja telah melakukan hubungan seksual dan 34\% remaja aktif secara seksual (2). Sekitar 6\% kehamilan remaja terjadi akibat aktivitas seksual sebelum menikah (3). Hasil Survei Kesehatan Reproduksi Remaja Indonesia (SKRRI) tahun 2007 menunjukkan bahwa sebesar 6,4\% remaja laki-laki dan 1,3\% remaja perempuan telah melakukan hubungan seks pranikah (4). Studi terdahulu tentang perilaku seks pranikah remaja di Indonesia, memperoleh hasil bahwa sekitar 25\% - 51\% remaja telah berhubungan seks pranikah (5). Komunikasi antara orang tua dan remaja merupakan proses penyampaian pesan atau informasi berupa keyakinan, sikap, nilai, harapan dan pengetahuan. Selain itu, komunikasi yang baik merupakan faktor pelindung untuk mencegah remaja melakukan perilaku seksual pranikah (6). Bimbingan orang tua dapat memberikan gambaran atau pandangan mengenai batasan perilaku seksual yang baik atau tidak baik, sehingga anak dapat mengerti batasan mereka dan membuat keputusan yang bertanggung jawab (7). Komunikasi orang tua dengan remaja memegang peranan penting dalam membina hubungan. Orang tua yang kurang bisa berkomunikasi dengan anak akan menimbulkan konflik sehingga berdampak pada perilaku seksual remaja (8).

Survei Demografi dan Kesehatan Indonesia tahun 2012 menyebutkan, sebagian besar remaja usia 15-19 tahun baik laki-laki maupun perempuan berdiskusi mengenai kesehatan reproduksi dengan teman sebaya (57,6\%) dan berdiskusi dengan guru (45,1\%). Proporsi remaja yang berdiskusi dengan ibu juga cukup besar pada remaja perempuan (42,1\%). Survei Kesehatan Reproduksi Remaja di Yogyakarta tahun 2011, mengemukakan bahwa remaja sulit untuk berkomunikasi tentang seksualitas dengan ayah (8,81\%) dibandingkan dengan ibu (4,41\%) (4). Remaja ber- pendapat bahwa komunikasi dengan ibu sangat mudah dilakukan. Melihat kesenjangan tersebut, upaya yang dapat dilakukan untuk mencegah perilaku seksual remaja berisiko adalah melibatkan komunikasi orang tua dan remaja di rumah.

Berdasarkan studi pendahuluan, tingkat pacaran pada siswa SMK cukup tinggi. Siswa SMK mendapatkan informasi kesehatan reproduksi remaja pada saat Masa Orientasi Siswa (MOS). Siswa SMK tidak mendapatkan mata pelajaran biologi atau pengetahuan alam, sehingga mereka mencari tambahan informasi mengenai kesehatan reproduksi remaja dari berbagai sumber. Penelitian ini penting dilakukan agar remaja mendapat informasi dan pengetahuan yang benar tentang seksualitas. Penelitian ini dilakukan dengan tujuan untuk mengetahui hubungan antara komunikasi orang tua-anak tentang seksualitas dan perilaku seksual remaja pranikah.

\section{METODE}

Jenis penelitian observasional dengan rancangan cross-sectional dilaksanakan di SMK "A" Yogyakarta. Variabel bebas penelitian yaitu komunikasi orang tua tentang seksualitas, variabel terikat yaitu perilaku seksual pranikah dan variabel luar yaitu jenis kelamin, struktur keluarga, efikasi diri dan penggunaan alkohol /NAPZA.

Subjek penelitian adalah seluruh siswa dan siswi SMK yang dipilih dan memenuhi kriteria inklusi dan eksklusi. Jumlah sampel berjumlah 205 siswa dengan teknik pengambilan sampel untuk tiap-tiap jurusan dengan menggunakan proportional random sampling. Instrumen penelitian tentang perilaku seksual diadopsi dari penelitian Sudirman (9). Instrumen penelitian komunikasi orang tua dan remaja tentang seksualitas menggunakan kuesioner dari penelitian Burgess, Dziegielewski (10) dalam Rosdarni, Dasuki (11). Instrumen tentang efikasi diri menggunakan skala yang dimodifikasi dari Adolescent Self-Efficacy Scale for Sexual Abstinence (ASESSA) yang disusun oleh Hulton yang sudah dilakukan uji validitas dan reliabilitas oleh Dewi $(12,13)$. Instrumen tentang struktur keluarga (tinggal dengan) terdiri dari tinggal dengan kedua orang tua, ayah saja, ibu saja, atau wali. Instrumen tentang penggunaan alkohol/NAPZA diadopsi dari penelitian Sudirman (9).

\section{HASIL}

Tabel 1 menunjukkan karakteristik responden. Lebih dari 50 persen remaja melakukan perilaku 
seksual pranikah berisiko. Lebih dari 55 persen komunikasi kesehatan reproduksi dan seksualitas antara orang tua dan remaja termasuk dalam kategori tidak baik.

Tabel 1. Karakteristik responden

\begin{tabular}{|c|c|c|}
\hline Variabel & $\mathbf{n}$ & $\%$ \\
\hline \multicolumn{3}{|l|}{ Perilaku seksual pranikah } \\
\hline Tidak berisiko & 98 & 47,80 \\
\hline Berisiko & 107 & 52,20 \\
\hline \multicolumn{3}{|c|}{ Komunikasi orang tua tentang seksualitas } \\
\hline Baik & 89 & 43,41 \\
\hline Tidak baik & 116 & 56,59 \\
\hline \multicolumn{3}{|l|}{ Struktur keluarga } \\
\hline Ibu saja atau ayah saja & 24 & 11,71 \\
\hline Kedua orang tua & 181 & 88,29 \\
\hline \multicolumn{3}{|l|}{ Efikasi diri } \\
\hline Tinggi & 126 & 61,46 \\
\hline Rendah & 79 & 38,54 \\
\hline \multicolumn{3}{|l|}{ Penggunaan alkohol/NAPZA } \\
\hline Tidak adiksi & 154 & 75,12 \\
\hline Adiksi & 51 & 24,88 \\
\hline \multicolumn{3}{|l|}{ Jenis kelamin } \\
\hline Perempuan & 78 & 38,05 \\
\hline Laki-laki & 127 & 61,95 \\
\hline \multicolumn{3}{|l|}{ Umur } \\
\hline 15-16 tahun & 178 & 86,83 \\
\hline 17-18 tahun & 27 & 13,17 \\
\hline \multicolumn{3}{|l|}{ Pendidikan ayah } \\
\hline SD & 28 & 13,66 \\
\hline SMP & 32 & 15,61 \\
\hline SMA & 112 & 54,63 \\
\hline D3/Sarjana & 33 & 16,10 \\
\hline \multicolumn{3}{|l|}{ Pendidikan ibu } \\
\hline SD & 37 & 18,05 \\
\hline SMP & 24 & 11,71 \\
\hline SMA & 115 & 56,10 \\
\hline D3/Sarjana & 29 & 14,15 \\
\hline \multicolumn{3}{|l|}{ Pekerjaan ayah } \\
\hline Tidak bekerja & 13 & 6,34 \\
\hline Pegawai negeri & 11 & 5,37 \\
\hline Pegawai swasta & 100 & 48,78 \\
\hline Wirausaha/wiraswasta & 81 & 39,51 \\
\hline \multicolumn{3}{|l|}{ Pekerjaan ibu } \\
\hline Tidak bekerja/IRT & 109 & 53,17 \\
\hline Pegawai negeri & 3 & 1,46 \\
\hline Pegawai swasta & 43 & 20,98 \\
\hline Wirausaha/wiraswasta & 50 & 24,39 \\
\hline \multicolumn{3}{|c|}{ Diskusi tentang kesehatan reproduksi } \\
\hline Ibu & 63 & 30,73 \\
\hline Ayah & 9 & 4,39 \\
\hline Teman & 98 & 47,80 \\
\hline Saudara & 7 & 3,41 \\
\hline Guru & 11 & 5,37 \\
\hline Petugas kesehatan & 16 & 7,80 \\
\hline Pemuka agama & 1 & 0,49 \\
\hline
\end{tabular}

Tabel 2 menunjukkan bahwa komunikasi orang tua tentang seksualitas, jenis kelamin, efikasi diri dan penggunaan alkohol/NAPZA berpengaruh terhadap perilaku seksual pranikah. Struktur keluarga yang baik tidak berpengaruh terhadap perilaku seksual pranikah. Komunikasi orang tua yang tidak baik pada remaja berpeluang 1,3 kali lebih besar meningkatkan perilaku seksual pranikah berisiko dibandingkan dengan komunikasi orang tua yang baik pada remaja.
Analisis multivariabel menunjukkan peningkatan komunikasi orang tua tentang seksualitas yang tidak baik terhadap terjadinya perilaku seksual pranikah yang berisiko pada remaja. Analisis bivariabel menunjukkan adanya hubungan secara statistik maupun praktis, sedangkan setelah mempertimbangkan variabel lain, tidak terdapat hubungan antara komunikasi orang tua tentang seksualitas dengan perilaku seksual pranikah. Terdapat pengaruh penggunaan alkohol/NAPZA terhadap komunikasi orang tua dan perilaku seksual pranikah. Hal ini menunjukkan efek modifikasi.

Tabel 2. Odd Ratio variabel yang berpengaruh terhadap perilaku seksual pranikah remaja

\begin{tabular}{|c|c|c|c|c|c|c|}
\hline \multirow{3}{*}{ Variabel } & \multicolumn{4}{|c|}{$\begin{array}{c}\text { Perilaku seksual } \\
\text { pranikah }\end{array}$} & \multirow{3}{*}{$\begin{array}{c}\text { Crude } \\
\text { OR } \\
\text { (95\% CI) }\end{array}$} & \multirow{3}{*}{$\begin{array}{c}\text { Adjusted } \\
\text { OR } \\
(95 \% \mathrm{CI})\end{array}$} \\
\hline & \multicolumn{2}{|c|}{$\begin{array}{l}\text { Tidak } \\
\text { berisiko }\end{array}$} & \multicolumn{2}{|c|}{ Berisiko } & & \\
\hline & $\mathbf{n}$ & $\%$ & $\mathbf{n}$ & $\%$ & & \\
\hline \multicolumn{7}{|c|}{ Komunikasi orang tua tentang seksualitas } \\
\hline Baik & 50 & 56,18 & 39 & 43,82 & & \\
\hline Tidak baik & 48 & 41,38 & 68 & 58,62 & \multicolumn{2}{|c|}{$(1,03-3,17)(0,78-2,63)$} \\
\hline \multicolumn{7}{|c|}{ Struktur keluarga } \\
\hline Ibu/ayah saja & 12 & 50,00 & 12 & 50,00 & & \\
\hline Kedua orang tua & 86 & 47,51 & 95 & 52,49 & $\begin{array}{c}1,10 \\
(0,47-2,58)\end{array}$ & \\
\hline \multicolumn{7}{|l|}{ Efikasi diri } \\
\hline Tinggi & 69 & 54,76 & 57 & 45,24 & & \\
\hline Rendah & 29 & 36,71 & 50 & 63,29 & $\begin{array}{c}2,08 \\
(1,17-3,71)\end{array}$ & $\begin{array}{c}1,42 \\
(0,74-2,70)\end{array}$ \\
\hline \multicolumn{7}{|c|}{ Penggunaan alkohol/NAPZA } \\
\hline Tidak adiksi & 84 & 54,55 & 70 & 45,45 & & \\
\hline Adiksi & 14 & 27,45 & 37 & 72,55 & $\begin{array}{c}3,17 \\
(1,58-6,33)(\end{array}$ & $\begin{array}{c}2,49 \\
(1,18-5,26)^{*}\end{array}$ \\
\hline
\end{tabular}

\section{BAHASAN}

Secara umum penelitian ini telah berhasil membuktikan keterkaitan antara komunikasi orang tua tentang seksualitas dengan perilaku seksual pranikah pada remaja. Berdasarkan analisis bivariabel terdapat hubungan yang bermakna antara komunikasi orang tua tentang seksualitas yang tidak baik dengan perilaku seksual pranikah berisiko pada remaja. Hal ini serupa dengan penelitian Ryan, Jorm menjelaskan bahwa komunikasi orang tua dengan remaja yang baik memiliki efek positif terhadap perilaku seksual pranikah yang berisiko (14). Komunikasi yang positif antara orang tua dan anak dapat membantu remaja membangun nilai individu dan membuat keputusan yang sehat (15).

Komunikasi orang tua tentang seksualitas tidak berhubungan dengan perilaku seksual pranikah pada remaja. Hal ini serupa dengan penelitian Ayalew, Mengistie yang menunjukkan bahwa komunikasi tentang seksual dan masalah kesehatan reproduksi dengan orang tua memiliki hubungan yang tidak 
signifikan dengan perilaku seksual pranikah pada remaja (16).

Kualitas komunikasi antara orang tua dan remaja berupa komunikasi yang intensif, diskusi, bertukar pendapat dan pemecahan masalah secara bersama dapat menghindarkan remaja dari perilaku seksual pranikah (17). Masih terdapat beberapa hambatan antara lain remaja masih merasa tidak mendapatkan pengetahuan tentang seksualitas yang cukup dari orang tuanya dikarenakan budaya Indonesia masih menganggap tabu untuk mendiskusikan seksualitas kepada anak secara terbuka, merasa tidak nyaman, dan malu (18).

Tidak terdapat hubungan yang signifikan antara komunikasi orang tua tentang seksualitas dengan perilaku seksual pranikah pada remaja setelah mempertimbangkan variabel jenis kelamin. Hal ini sejalan dengan penelitian Wilson and Koo dengan tidak menemukan perbedaan jenis kelamin yang signifikan antara pengaruh komunikasi orang tua - anak tentang seksualitas berdasarkan jenis kelamin orang tua atau anak. Penelitian Wilson and Koo menyebutkan kecenderungan ibu berbicara dengan anak laki-laki dan perempuan tentang seksualitas, dibandingkan dengan ayah yang jarang berbicara kepada anak laki-laki maupun perempuan (19).

Tidak terdapat hubungan antara stuktur keluarga dengan perilaku seksual pranikah. Penelitian ini sejalan dengan penelitian Maimunah yang menunjukkan bahwa status pernikahan dan pendidikan orang tua tidak berpengaruh yang signifikan terhadap perilaku seksual pada remaja (20). Tidak terdapat hubungan antara komunikasi orang tua tentang seksualitas dengan perilaku seksual pranikah setelah mempertimbangkan variabel efikasi diri. Hal ini dapat terjadi mungkin terdapat variabel lain yang lebih memengaruhi perilaku seksual pranikah, sehingga ketika diuji secara bersama-sama maka efikasi diri menjadi tidak berpengaruh terhadap perilaku seksual pranikah remaja. Efikasi diri merupakan faktor kunci sumber tindakan manusia (human agency), apa yang seseorang pikirkan, percayai dan rasakan akan memengaruhi mereka untuk bertindak (21). Efikasi diri yang rendah dapat membuat remaja tidak bisa menolak perilaku seksual pranikah yang berisiko.

Komunikasi orang tua tentang seksualitas tidak berhubungan dengan perilaku seksual pranikah remaja setelah mempertimbangkan variabel penggunaan alkohol/NAPZA. Hal ini serupa dengan penelitian Mogro-Wilson yang memperoleh hasil tidak terdapat hubungan yang bermakna antara kualitas hubungan orang tua-anak dengan penggunaan alkohol pada remaja (22). Penggunaan alkohol/NAPZA berpengaruh terhadap komunikasi orang tua tentang seksualitas dengan perilaku seksual pranikah. Hal ini serupa dengan penelitian Abebe, Tsion yang menunjukkan bahwa remaja yang mengonsumsi alkohol berpeluang 7 kali lebih besar melakukan seksual pranikah berisiko dibandingkan dengan remaja yang tidak mengonsumsi alkohol (22).

\section{SIMPULAN}

Komunikasi orang tua tentang seksualitas berhubungan dengan perilaku seksual pranikah pada remaja. Setelah mempertimbangkan variabel jenis kelamin, efikasi diri, dan penggunaan alkohol/NAPZA, komunikasi orang tua tentang seksualitas tidak berhubungan dengan perilaku seksual pranikah remaja.

Pembekalan kesehatan reproduksi remaja dan masalah-masalah seksualitas remaja penting disampaikan melalui bimbingan konseling oleh guru bimbingan. Konseling tidak diberikan satu waktu saat masa orien- tasi siswa. Komunikasi terbuka dengan remaja tentang kesehatan reproduksi penting dilakukan oleh orang tua. Topik seksualitas dan kesehatan reproduksi bukan masalah tabu dan penting didiskusikan agar remaja mendapatkan informasi yang benar.

\section{Abstrak}

Tujuan: Penelitian ini dilakukan untuk mengetahui hubungan antara komunikasi orang tua-anak tentang seksualitas dan remaja perilaku seksual pranikah. Metode: Penelitian ini melibatkan 205 siswa di SMA "A" Yogyakarta. Analisis data dengan uji regresi logistik chi-square dan regresi logistik. Hasil: Penelitian ini menunjukkan bahwa tidak ada hubungan yang signifikan ( $>0,05)$ antara komunikasi orang tua tentang seksualitas terhadap perilaku seksual pranikah pada remaja dengan skor OR 1,43 (95\% CI; 0,78-2,63). Hasil analisis komunikasi seksualitas orang tua setelah mempertimbangkan jenis kelamin, self efficacy, dan alkohol/obat menggunakan variabel menyumbang 5,7\% pada perilaku seksual pra-nikah yang berisiko. Simpulan: Tidak ada hubungan antara komunikasi orang tua-anak tentang seksualitas dan remaja perilaku seksual pranikah. 
Kata kunci: komunikasi orang tua-anak; perilaku seksual pranikah; remaja

\section{PUSTAKA}

1. Irianto K. Memahami Seksualitas. Bandung: Sinar Baru Alegensindo; 2010.

2. CDC. Youth risk behavior surveillance-United States 2013. Morbidity \& Mortality Weekly Report. 2014;63(4):24-9.

3. Kost K, Henshaw S. US teenage pregnancies, births and abortions, 2010: National and state trends by age, race and ethnicity. New York: Guttmacher Institute. 2014.

4. SKKR. Survei Kesehatan Reproduksi Remaja Provinsi DIY. Yogyakarta: Badan Pemberdayaan Perempuan dan Masyarakat Provinsi Daerah Istimewa Yogyakarta dan PT. Cendikia Utama; 2011.

5. Utomo ID, McDonald P. Adolescent reproductive health in Indonesia: Contested Values and Policy in action. Studies in Family Planning Journal. 2009;40(2):133-46.

6. Gumban GD, Martos RJB, Klyde, Racidon, Ivy. Let's Talk About Sex: Parental Communication and Sexual Behavior of Male Filipino Youth. Asia Pacific Journal of Multidisciplinary Research. 2016;4(2):130-9. 9

7. Cupp PK, Atwood KA, Byrnes HF, Miller BA, Fongkaew W, Chamratrithirong A, et al. The Impact of Thai Family Matters on ParentAdolescent Sexual Risk Communication Attitudes and Behaviors. Journal of health communication. 2013;18(11):1384-96.

8. Wamoyi J, Fenwick A, Urassa M, Zaba B, William S. Parent-Child Communication about Sexual and Reproductive Health in Rural Tanzania: Implications for Young People's Sexual Health Interventions. Repro Health. 2010;7(6):1 -18.

9. Sudirman RM. Peran Teman Sebaya dan Paparan Media pornografi Terhadap Perilaku Seksual Remaja Di Sekolah Menengah Kejuruan Tunas Bangsa Kabupaten Subang: Universitas Gadjah Mada; 2014.

10. Burgess V, Dziegielewski SF, Green CE. Improving Comfort about Sex Communication between Parents and Their Adolescents: Practice-Based Research within A Teen Sexuality Group. Brief Treatment and Crisis Intervention. Brief Treatment and Crisis Intervention. 2005;5(4):379-90.

11. Rosdarni, Dasuki D, Waluyo SD. Pengaruh Faktor Personal terhadap Perilaku Seksual Pranikah pada Remaja. Jurnal Kesmas. 2015;9(3):214-21.

12. Hulton L. Self-Efficacy for Sexual Abstinence and Gender Differences in a Rural Adolescent Population (Serial Online). www. ent-st. com/ESTOPA/presentations/Hulton. pdf. Diakses pada tanggal 12 Februari 2009. 2006.

13. Dewi INCT. Pengaruh Faktor Personal Dan Lingkungan Terhadap Perilaku Seksual Pranikah Pada Remaja Di SMA Negeri 1 Baturaden dan SMA Negeri 1 Purwokerto: Universitas Diponegoro Semarang; 2009.

14. Ryan SM, Jorm AF, Lubman DI. Parenting factors associated with reduced adolescent alcohol use: a systematic review of longitudinal studies.
Australian and New Zealand Journal of Psychiatry. 2010;44(9):774-83.

15. Lagina N. Parent-Child Communication: Promoting Sexually Health Youth. Advocates for Youth. 2010.

16. Ayalew M, Mengistie B, Semahegn A. Adolescent-parent communication on sexual and reproductive health issues among high school students in Dire Dawa, Eastern Ethiopia: a cross sectional study. Reproductive Health. 2014;11(1):77

17. Negeri EL. Assessment of risky sexual behaviors and risk perception among youths in Western Ethiopia: the influences of family and peers: a comparative cross-sectional study. BMC public health. 2014;14(1):301.

18. Ayehu A, Kassaw T, Hailu G. Young People's Parental Discussion about Sexual and Reproductive Health Issues and Its Associated Factors in Awabel Woreda, Northwest Ethiopia. Repro Health. 2016;13(19):1 -8

19. Wilson EK, Koo HP. Mothers, fathers, sons, and daughters: gender differences in factors associated with parent-child communication about sexual topics. Reproductive Health. 2010;7(1):1. 10.

20. Maimunah S. Pengaruh Faktor Keluarga terhadap Perilaku Seksual Remaja. Seminar psikologi dan Kemanusiaan. 2015:359-62.

21. Bandura A. Social Cognitive Theory. Handbook of Theories of Social Psychology. 2011:1349.

22. Mogro-Wilson C. The influence of parental warmth and control on Latino adolescent alcohol use. Hispanic Journal of Behavioral Sciences. 2008;30(1):89-105. 23. Abebe M, Tsion A, Netsanet F. Living with parents and risky sexual behaviors among preparatory school students in Jimma zone, South west Ethiopia. African Health Sciences. 2013;13(2):498-506. 
Berita Kedokteran Masyarakat, Volume 33 No. 10 Tahun 2017 